\title{
ARTIG0S
}

\section{A DIÁSPORA JUDAICA EM ROMA DAS ORIGENS ATÉ NERO(I).}

\author{
ENIO ALOISIO FONDA \\ Regente ca Cadeira de Lingua e Literatura Latinä da \\ Faculdade de Filosofia, Ciências e Letras de Assis (SP).
}

As primeiras relações que os romanos travaram com os judeus remontam aos tempos dos Macabeus (161 a. C.), quando o senado romano procurou amistar, para seus fins políticos, o pequeno reino da Judéia (1). Roma, evidentemente, mirava conservar intacto e forte êsse reino, pôsto entre o Egito e a Síria, a fim de que estas duas potências permanecessem isoladas, e cuja possível união teria fàcilmente baldado qualquer tentativa de expansão e de conquista por parte de Roma no Oriente Médio (2) .

A primeira comunidade judaica ter-se-ia fixado em Roma imediatamente após a conclusão da aliança, tomando sempre maior vulto com o desenrolar sucessivo dos acontecimentos políticos que culminariam com a integração da nacionalidade judaica esparsa pelo mundo, ao domínio político romano.

E' fácil, contudo, conjeturar-se, que uma verdadeira diáspora, lato sensu, de que se tenha notícia segura. só tenha surgido na capital do mundo, denois de 63 a. C., quando Pompeu, tendo tomado Jerusalém e reduzido à província romana o reino dos Selêucidas e a Síria, levou a Roma o rei da Judéia, Aristóbulo, que substituíu por Hircano (3), bern como muitos prisioneiros para o seu triunfo, e que depois vendeu como escravos (4). Pouco depois, Herodes rece-

\footnotetext{
(1). - I Mac., VIII, 1 et seq. e 17-22; XII, 1-4; XIV, 16-19 e 24; Flávio Josefo Antiquitatum Iudaicarum Libri, XII, cap. X (xv1), 6 (p. 474-475) . Cf. XIII, 5, 7, 9. - Servimo-nos da ediçăo bilingưe (grego-latina) de Gullelmus Dindorfius, publicada em Paris por Firmin-Didot, em 1929.

(2) . - Cf. S. Scaglia - Manuale di Archeologia Cristiana. Roma, Libreria Editrice Religiosa Francesco Ferrarl, 1911, p. 24, nota no 1.

(3). - Flávio Josefo - Ant. Iud. (cit.), XX, $10 .(8), 27-33 ; \mathrm{XIV}, 4$ (8); XIV, 8, 5 e XII, 9, 2

(4). - Fílon - Legatio ad Caium, 23. Cf. Flávio Josefo - Bellum Iudaicum, I, 6-7 (Ediçáo de Guilelmus Dindorfius, publicada em Paris por Firmin-Didot, em 1929). Apiano - POMAIKA (De bello Mithridatico), 117.
} 
bera de Antônio o trono de Jerusalém (5). Sob o seu reino, a emigração judaica continuou, aumentando consideràvelmente a presença do elemento hebreu em Roma.

Em 59 a. C. a colônia hebraica era tão numerosa e turbulenta que Cícero, ao defender Lúcio Valério Flaco, adversário dêles, divisara entre os assistentes muitos judeus, vendo-se obrigado a abaixar seu tom de voz para não ser ouvido por êles, presentes em grande número no Forum e que alvoroçavam as assembléias populares.

Eis, na integra, as palavras de Cícero:

Sequitur auri illa invidia Iudaici. Hoc nimirum est illud, quod non longe a gradibus Aureliis haec causa dicitur; ob hoc crimen hic locus abs te, Laeli, atque illa turba quaesita est. Scis, quanta sit manus, quanta concordia, quantum valeat in concionibus. Summissa voce agam, tantum ut iudices audiant. Neque enim desunt, qui istos in me, atque in optimum quemque incitent: quos ego, id facilius faciant, non adiuvabo.

Quum aurum, Iudaeorum nomine, quotannis ex Italia, et ex omnibus provinciis Hierosolyma exportari soleret, Flaccus sanxit edicto, ne ex Asia exportari liceret. Quis est, iudices, qui hoc non vere laudare possit? Expotari aurum non oportere, quum saepe antea senatus, tum, me consule, gravissime iudicavit. Huic autem barbarae superstitioni resistere, severitatis; multitudinem Iudaeorum, flagrantem nonnunquam in concionibus, pro republica contemnere, gravitatis summae fuit (6).

Das palavras de Cícero ressalta não só o número considerável de judeus em Roma, mas sobretudo sua coesão moral e espírito de empreendimento. E se tomarmos, a seguir, em consideração as palavras de Cícero:

Quum aurum, Iudaeorum nonine, quotannis ex Italia, |... Hierosolyma exportari soleret,

ter-se-á tôda razão para crer que em 59 a . C. a diáspora judaica de Roma tinha de ser bem mais antiga que a chegada dos escravos de Pompeu, três anos antes, e que êstes teriam apenas aumentado consideràvelmente o número daqueles que desde muito para lá vieram especialmente de Alexandria, Cirene e da Äfrica proconsular (7), que perfaziam o celeiro de Roma. Nada mais natural, portanto, que judeus, negociantes por natureza, tenham procurado seu campo de comércio em Roma (8). Mas a afluência em massa de judeus para

(5). - Tácito - Historiae (Vespasianus), V, 9. Flávio Josefo - Ant. Iud., XIV, 5.

(6). - Cícero - Oratio pro Lucio Valerio Flacco, XXVIII.

(7)..- Cf. G. Rlcciott1 - Storia del Popolo d'Israele. Torino, Societa Editrice Internazionale, 1950 , vol. II, p. 230 .

(8) . - Idem - ibidem, vol, II, p. 230. 
Roma não se encerrou com a chegada dos prisioneiros feitos por Pompeu, porque em 51 a. C. trinta mil judeus prisioneiros foram vendidos pelo legado de Crasso, vindo assim a aumentar a população israelita de Roma (9).

Júlio César procurou apôio nos judeus durante as guerras civis, chegando a lhes conceder amplos privilégios (10); tanto assim que the choraram a morte, velando no Foro durante diversas noites ao redor de suas cinzas (11), e homens livres e escravos de origem judia percorriam as ruas da cidade com gritos de dor e pesar (12) .

Continuaram tolerados sob Augusto que, aplicando a política do tio, lhes foi bastante benévolo, ao ponto de recomendar que as autoridades os não esquecessem nas obras assistenciais dadas ao povo em seu nome, e que se protelasse a distribuição da ajuda, caso essa caísse no sábado, para se thes não ofender as consciências.

A tolerância de Augusto chegou até a permitir aos judeus da "diáspora" o direito de angariar fundos para o templo de Jerusalém (13) .

Apripa, gênro e confidente íntimo do Imperador, integrando uma legação à côrte de Herodes, mandou oferecer no templo um sacrifício de cem bois (14). Fílon refere que o próprio Augusto instituíra um sacrifício diário e perpétuo de um touro e dois cordeiros. Júlia, fillha de Augusto, doou ao templo vasos preciosos, cálices de ouro e outros objetos de valor (15). Relata ainda Suetônio que o Imperador louvou seu filho Caio porque, tendo êste passado por Jerusalém, não se esquecera de oferecer um sacrifício ao Deus dos hebreus (16). Tácito salienta que uma das suas preocupações era seu crescimento (17). De fato, em 4 a . C., quando, como diz Josefo, viera a Roma um impostor que pretendia ser Alexandre, filho de Herodes, todos os judeus sairam da cidade para recebê-lo, e uma multidão sem conta aguardava nas ruas sua passagem (18).

Resta, agora, apresentar duas fontes, ambas de Josefo, e que testemunham o número relativamente ingente de judeus em Roma no ano 4 a. C.

\footnotetext{
(9). - Flávio Josefo - Antiq. Iud., XIV, 12.

(10) . - Flávio Josefo - Contra Apionem, II, 4; Antiq. Iud., XIV, 10, 6 et seq.; XVI, 6, 2 et seq.; Bellum Iudaicum, VI, 6, 2; Filon - Lagatio ad Caium, 23.

(11). - Suetônio - Divus Iulius, LXXXIV.

(12) . - Cícero - Philip., I, 2, 12, 42.

(13). - Filon - Legatio ad Caium.

(14). - Flávio Josefo - Anti. Iud., XIV, 26.

(15). - Fílon - Lagatio ad Caium.

(16). - Suetônio - Octavius Augustus, XCIII.

(17). - Tácito - Historiae, V, 5: "generandi amor... augendae multitudini consulitur".

(18). - Flávio Josefo - Bellum Iudaicum, II, 7; Antiq. Iuda, XVII, 11.
} 
Trata-se de uma embaixada composta de cinqüienta representantes da Palestina, que viera a Roma para conseguir de Augusto concessões relativas ao livre exercício de suas próprias leis, e à qual se juntara tôda a etnia judaica de Roma, em número que ia além de oito mil. sem contar mulheres e criancas (19).

No reinado de Tibério, porém, deu-se um caso rumoroso que veio a prejudicar o bem-estar da comunidade judia em Roma. Essa notícia merece especial atenção porque foi transmitida por três historiadores: Tácito. Flávio Josefo e Suetônio. Tibério. em 19 d. C., expulsara de Roma quatro mil judeus em virtude de um edito que interdizia os cultos orientais. Josefo não só constata a expulsão, mas procura motivá-la como sendo consequiência de um impostor de origem judaica a quem se associaram outros três espertos, que, ludibriando a boa fé de uma matrona romana por nome Fúlvia, prosélita da lei mosaica, espôsa de Saturnino, confidente de Tibério, tornaram-se-lhe moderadores de consciência. conseguindo dela inclusive a entrega de jóias destinadas ao tesouro do templo de Jerusalém, mas que dissiparam em seu próprio benefício (20) .

Acusados a Tibério por Saturnino, marido da vítima enganada, por instigação dela mesma, o Imperador baixou então o decreto de banimento.

Vejamos primeiro o testemunho de Tácito, que contràriamente a Suetônio dá a conhecer além do número global dos banidos também o lugar de destinação dos homens judeus bem como a função que deveriam desempenhar nacpuelas terras infestas de salteadores:

Actum est de sacris aegyptiis iudaicisque pellendis: factumque patrum consultum, ut quattuor millia libertini generis, ea superstitione infecta, quis idonea aetas, in insulam Sardiniam veherentur, coercendis illic latrociniis, et, si ob gravitatem coeli interissent, vile damnum; ceteri cederent Italia, nisi certam ante diem profanos ritus exuissent (21).

Suetônio confirma a proscrição dos cultos estrangeiros e a expulsão de seus adeptos, especificadamente da juventude judia de Roma, omitindo porém o número dos banidos:

Externas cerimonias, Aegyptios Iudaicosque ritus compescuit; coactis, qui superstitione ea tenebantur, religiosas vestees cum instrumento omni comburere. Iudaeorum iuventutem, per speciem sacramenti, in provincias gravioris coeli distribuit: reliquos gentis

(19). - Flávio Josefo - Antiq. Iud., XVII, xi (xii), 1 (p. 685) .

(20). - Flávio Josefo - Antiq. Iud., XVIII, 3, 5 (p. 71).

(21) . - Tácito - Annales, II, 85. 
eiusdem, vel similia sectantes, Urbe summovit, sub poena perpetuae servitutis, nisi obtemperassent (22).

A seguir, importará apresentar o texto de Josefo em que descreve a tragédia da diáspora judia em Roma:

Nunc autem ad ea narranda revertor, quae per id tempus Iuadaeis Romae degentibus contigenunt |...|. Erat vir genere Iudaeus, patria quidem sua profugus, ut qui accusaretur quod contra leges fecerat et poenam metueret, in omnibus vero nequam et improbus. Is tum Romae degens, se quidem legis Mosaicae interpretem profitebatur, et tribus aliis per onnia sui similibus in societatem ascitis, Fulviae, feminae nobili, quae, legem Mosaicam amplexa, sese illis in disciplinam tradiderat, persuadent ut purpuram et aurum in templum Hierosolymitanum mitteret: qui quum ea accepissent, in proprios usus verterunt et profuderunt, quem in finem ea etiam ab initio postulaverant. Quo fit ut Tiberius (ei quippe rem indicaverat quo amico utebatur Saturninus Fulviae maritus ex uxoris instigatione) iuberet cunctos Iudaeos Roma pelli. Ex quibus consules delectu habito quattuor millia nilitum in Sardiniam insulam miserunt: plurimos etiam, qui ut servarent patria instituta militiam detrectarunt; poenis affecerint. Atque ita, propter quattior hominum nequitiam, Iudaei eiecti sunt e civitate (23).

Uma divergência, contudo, se verifica entre os três historiadores, pois Tácito engloba ao número dọs exilados também os sectários de crenças egípcias, Suetônio, que fala da expulsão de judeus e dos adeptos de ritos egípcios, não especifica algarismo algum dos expulsos, enquanto Josefo determina categòricamente como sendo de quatro mil o número dos judeus banidos.

Quatro mil homens aptos para as armas, corresponderiam a uma cifra total de pelo menos dez mil judeus fixados em Roma naqueles momentos particularmente difíceis. Este cálculo, na verdade, se concilia com aquela outra notícia de Flávio Josefo já citada acima (24), segundo a qual vinte e três anos antes os judeus da diáspora romana iam além de oito mil, não figurando mulheres e crianças .

E' necessário admitir que Flávio Josefo tenha dado aqui o total preciso de quatro mil, alusivo aos homens judeus ùnicamente, ou então, que tenha exagerado bastante em relação a Tácito, que inclui no número específico ambas as partes atingidas pelo decreto imperial. Com relação ao total da população de Roma nos tempos de Augusto $(5$ a C. $)$, o dado que mais atenção merece, é o que atribui à ci-

(22). - Suetônio - Tiberius, XXXVI. Cf. Díon Cássio, LVII, 18, 5 (a) (ed. Weidmann, Berlin, 1955, 3 volumes), vol. 2, p. 577.

(23) . - Flávio Josefo - Antiq. Iud., XvirI, 3, 5 (p. 101).

(24). - Cf. nota n? 20 e 23 . 
dade a cifra de 320.000 plebeus de sexo masculino acima de dez anos de idade. Tomando em consideração a notória minoria de mulheres em Roma, pode-se calcular, em conjunto, perto de 600.000 o número dos habitantes de Roma, sem incluir escravos. Representariam, assim, os 10.000 judeus estabelecidos em Roma no ano $19 \mathrm{~d}$. C., aproximadamente uma septuagésima parte da população total de Roma (25) .

Mas, mesmo admitindo serem os 4.000 todos judeus, homens aptos para as armas, forçoso é reconhecer que êsses não representam de forma alguma o forte da comunidade judaica em Roma, porque os arregimentados eram todos libertini generis (26), alforriados portanto ou filhos dêstes. Acresce ainda o fato de muitos judeus, talvez uma grande maioria, terem preferido o exílio a assentar praça, por escrúpulo religioso, e que poucos tenham apostatado de sua fé (27). Finalmente resta a considerar o número dos judeus em condição de escravos, e em número não despiciendo, aos quais não fôra aplicada a medida imperial. Isso tudo leva a crer que na realidade, em Roma, a etnia judaica daquele tempo superasse os dez mil da conjectura aproximativa, e que seu número atingisse uma cifra bem mais considerável do que poderia sugerir uma análise numérica superficial e desconexa da tríplice fonte histórica: Tácito, Suetônio e Flávio Josefo.

Este último, não só constata a expulsão, como procura motivá-la como sendo consequiência de um impostor de origem israelita a quem se associaram outros três espertos que ludibriaram a boa fé de uma matrona romana, prosélita da Lei mosaica. Os minuciosos particulares com que Flávio Josefo pretende entrar no âmago do problema, atribuindo a quatro homens corruptos a responsabilidade de medida tão drástica, parecem aqui querer advertir ao leitor bem mais que o texto possa sugerir à primeira vista. Josefo, judeu que é, procura, coisa de tudo compreensível, abrandar a acusação que pesava sôbre a coletividade hebréia, dirigindo, não sem certa fôrça convincente, tôda culpa a homens que no fundo, de forma alguma, poderiam representar genèricamente tôda uma etnia (28).

Não houvesse uma prova anterior, poder-se-ia atenuar a gravidade do fato, mas Cícero, já em 59 a. C., logo 60 anos antes da expulsão decretada por Tibério (19 d. C.) referia-se ao odioso costume de os judeus enviarem, anualmente, ouro para Jerusalém, o que era julgado contrário ao interêsse público (29).

\footnotetext{
(25). - Cf. A. Harnack - Missione e Propagazione del Cristianesimo nei Primi Tre Secoli. Milano, Fratelli Bocca Editori, 1906, p. 6.

(26) . - Cf. Tácito - Annales, II, 85. Texto no número que provoca a nota no 21.

(27) . - Flávio Josefo - Antiq. Iud., XVIII, cap. III (p. 701) .

(28) . - Flávio Josefo - Antiq. Iud., XVIII, cap. III (IV) (p. 701) .

(29). - Cícero - Pro Lucio Valerio Flacco, XXVIII; texto no número que provoca a nota ne 6 .
} 
O clamoroso caso de Fúlvia coincide antes de mais nada no proselitismo proibido por lei (30) e que consistia na busca de novos adeptos, ou ainda na simples propaganda do judaismo entre as classes sociais mais elevadas de Roma.

A Sinagoga na diáspora (isto é, na dispersão, fora da Palestina), e especialmente em Roma, deverá, não há dúvida, ter sido tão ìntimamente ligada às tradições e às aspirações nacionais do povo de Israel que logo chegou a vivos impulsos apostólicos, alcançando assim seus resultados. A sêde de domínio e a ambição não só nos daria uma explicação satisfatória, mas os próprios fatos que levaram ao judaismo, como religião, a sofrer uma transformação interior que o obrigou a transpor as fronteiras da própria pátria.

O judeu sentia orgulho da missão de anunciar e levar ao mundo algo que interessasse a tôda a humanidade: o Deus único e a sua santa lei moral, e desta sua consciência manava, para êle, o dever do apostolado (31).

Seja como fôr, uma coisa é certa: o empênho zelante dos judeus em recrutar o maior número possível de adeptos em Roma, tornando a diáspora um "pequeno estado no próprio Estado" e, consequientemente, uma associação autônoma na Urbe. Isso tudo prevenia contra êles os espíritos da autoridades ciosa da romanitas e preservadora da mesma, para que se visse no proselitismo a ameaça séria, posta a solapar os alicerces de tôda uma cultura e civilização chegadas ao vértice, bem como o desmoronamento sócio-político-religioso de um povo, como o romano, que se considerava chamado a altos destinos.

A larga difusão do judaísmo provocara uma viva reação. O caso de Fúlvia, portanto, não representaria uma singularidade mas um caso comum e frequiente a que Tibério queria pôr fim para que não sucumbisse a res Romana no próprio coração do império.

Por tôdas essas coisas vê-se como o Imperador tinha bastas razões para assumir uma atitude repressiva, explicada aliás pelas razões de Estado se não outras, e que importava, antes de mais nada, garantir as instituições romanas, sèriamente ameaçadas a perecer, caso se não resistisse às influências provindas de fora.

O exílio dos judeus, provocado provàvelmente por Sejano, o todo-poderoso ministro de Tibério e inimigo dos judeus (32), parece não ter durado muito, porque o Imperador revogou o banimento após a queda dêste (31 d. C. ), reconfirmando-lhes os direitos obti-

(30). - Cícero - De Legibus, II, 8: "Separatim nemo habessit deos novos, sive advenas, nisi publice adscitos, privatim colunto".

(31) . - Paulo - Epistola aos Romanos, II, 19.

(32). - Fílon - Apud Eusébio: Cronicon, II, ad annum Christi 35 (Abrahae 2050) (= Migne - Patrologiae cursus completus, XIX, col, 537-538). 
dos de César e Augusto. Puderam assim voltar a Roma (33), tornando-se novamente numerosos (34).

Durante o reinado de Calígula (37-41 d. C.) viveram imperturbados. mas Cláudio expulsou-os novamente, em 49, embora no início lhes tivesse sido favorável especialmente em reconhecer os antigos privilégios de que gozavam (35).

A razão desta nova expulsão se patenteia na célebre passagem de Suetônio:

Iudaeos impulsore Chresto, assidue tumultuantes Roma expulit (36) .

Abro aqui um parêntese para elucidar que junto com os judeus talvez tivessem sido banidos também os cristãos por terem sido considerados como seita judaica, porque, pode ser, que Chrestus do qual fala Suetônio não fôsse, como pretendem alguns (37), um grego convertido ao judaísmo, mas sim um judeu que abraçara a fé cristã e cujas polêmicas na luta religiosa tivessem conturbado os espíritos de uns e outros, motivo por que o imperador Cláudio os englobasse como pertencentes à mesma religião, expulsando os adeptos das duas crenças estrangeiras sob a pecha de Iudaei tumultuantes.

Harnack (38) pretende ver na forma Chrestus um verdadeiro antropônimo muito empregado entre os pagãos que desconheciam a forma Christus. E L. Todesco (39), finalmente, conjetura que Suetônio pensasse, por um lapso, ao próprio Cristo agindo em Roma, e que se o Autor quisesse ter aludido a um judeu qualquer $\mathrm{cnm}$ êsse nome, teria escrito Chresto quodam impulsore.

Os Atos dos Apóstolos falam de um casal de origem judaica, Aquila e Priscila, que o apóstolo Paulo encontrou em Corinto pelo ano 51-52, ambos obrigados a abandonar Roma (40). A notícia dos Atos dos Apóstolos estaria assim em consonância com a indicação de Suetônio.

Díon Cássio (41) diz que o banimento sob Cláudio tornou-se de difícil execusão, reduzindo-se o Edito, por fim, à simples proibição

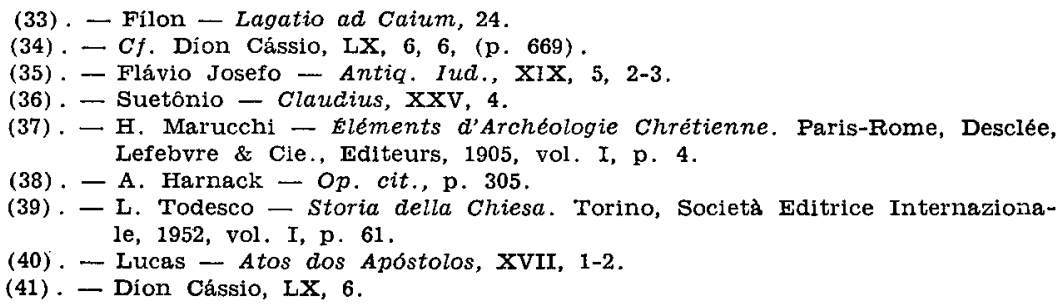


de suas assembléias (42). Mas, no caso, o exemplo de Aquila e Priscila é prova bastante para se admitir o cumprimento e a execução, embora parcial, das medidas tomadas por Cláudio contra os sequazes da religião mosaica.

Cabe perfeitamente aqui uma conjetura verossímel; pode ser também que se tratasse ùnicamente de judeus convertidos ao Cristianismo, e neste caso a frase de Suetônio deveria ser interpretada como alusiva a uma parte apenas de judeus simpatizantes da nova doutrina cristã. $U$ fato de Suetônio chamá-los Iudaeos, indistintamente, justificar-se-ia na falta de uma distinção nominal mais específica das duas facçôes antagônicas, só pelo fato de a comunidade cristã de então, em sua grande maioria, ainda provir do contingente judeu. Doutro ladó, a asserçãa de Díon Cássio sôbre a impossibilidade de uma aplicação categórica do exílio, vem a corroborar a tese da dificuldade em descernir os facciosos partidários de Chrestaus, culpados do tumulto, daquela outra facção não menos intransigente de judeus e provocada à luta doutrinária pela pregação da mensagem de Cristo .

Hoje em dia admite-se comumente, e não há sérias razões para não fazê-lo, que Chrestus, o qual segundo o historiador romano se erguera em impulsor dos tumultos entre os judeus, era o Christus ou seja o Messias do povo de Israel, quer dizer, era o partido dos adeptos da seita de Cristo, acêrca do qual discutia animosamente a Sinagoga e a Ecclesia. O impulsor, portanto, teria sido Cristo enquanto anunciado, pelos sectários da nova religião, como o Messias. Existiam, de fato, pelo ano 49-50, na colônia israelita de Roma pelo menos dois partidos em assíduo e violento contraste entre si: um dos que, aderindo à nova doutrina, admitiam o Messias (Cristo), e outro dos tradicionalistas que não o reconheciam. Evidentemente, os adeptos do primeiro eram os cristãos, chamados, por fácil permuta de vogal, tembém chrestiani em vez de christiani (43).

Como se acaba de constatar, as fontes se contradizem: os Atos dos Apóstolos (44) e Suetônio (45) falam claramente de uma expulsão levada a têrmo, ao passo que Díon Cássio (46) só releva a inexeqüibilidade do decreto imperial e a interdição das assembléias, donde há de se admitir que o Edito fôra aplicado com muita condescendência e remissão.

Sob Nero, porém, os judeus se consolidaram em Roma, chegando a ser numerosos (47) e talvez mais influentes de antes, pois ti-

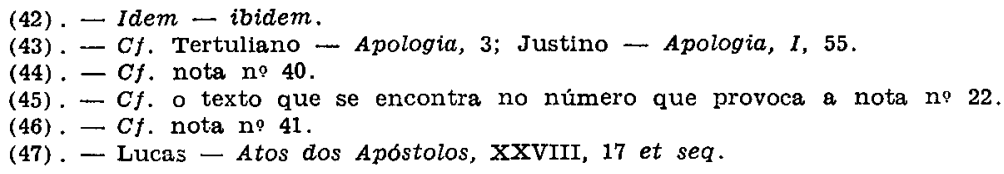


nham em Popéia Sabina, que de favorecida tinha passado à espôsa imperial depois do assassinato de Otávia, uma protetora junto do Imperador. Suas simpatias para com os judeus eram conhecidas universalmente (48). Flávio Josefo nô-la apresenta como timente a Deus, ou prosélita das portas (49); e, o que Tácito refere acêrca dos seus funerais, vem a confirmar sua condição de prosélita (50).

A condição privilegiada dos judeus ressalta ainda das palavras com que Flávio Josefo pretende defender Nero, alegando seus crimes a calúnias e à ação de maus conselheiros (51). Entre os privilegiados distacou-se, sem dúvida, um certo Alítiro, ator da côrte, muito estimado de Nero e Popéia, e graça ao qual Flávio Josefo foi admitido à audiência da Imperatriz que conseguiu do Príncipe a absolvição de uns sacerdotes israelitas implicados em acusações e que deveriam defender-se na presença do próprio Nero (52).

Pelo exposto, a condição dos judeus em Roma era substancialmente boa senão das melhores pelo ano $64 \mathrm{~d}$. C. Além do mais, tinham êles, por fôrça dos privilégios que César e Augusto lhes concederam, além da liberdade do culto, também a administração autônoma do patrimônio social e a faculdade de impor impostos obrigatórios, e, finalmente, em vista das prescrições da Lei sabática, eram inclusive isentos do serviço militar (53).

Não será descabido tecer agora umas considerações acêrca da constituição interna da comunidade da diâspora romana.

A colônia judaica de Roma era dividida em diversas synagogái (= congregações cívico-religiosas), ou, em têrmos romanos, collegia . Documentos seguros comprovam a existência de treze sinagogas, o

\footnotetext{
(48). - Flávio Josefo - Vita, 3.

(49). - Flávio Josefo - Ant. Iud., XX, 8, 11.

(50) . - Tácito - Annales, XVI, 6: "Corpus non igni abolitum, ut Romanus mos; sed, regum exterorum consuetudine, differtum odoribus conditur, tumuloque Iuliorum infertur". Cf. também Historiae, V, 5: "(Iudaef) corpora condere, quam crermare, e more Aegyptio"; C. Plinius Secundus Hist. Nat., XII, 41, 18: "Periti rerum asseverant (Arabiam) non terre tantum (scil. cinnamoni aut casiae) annuo fetu, quantum Nero princeps novissimo Poppeae suae die concremaverit".

(51). - Flávio Josefo - Antiq. Iud., $\mathrm{xX}, 8,3$ (p. 782) : "Nam multi Neronis historiam conscripserunt, quorum aliqui in gratiam, ut bene de se meriti, veritatem autem neglexerunt, alii vero ex odio et inimicitis sibi cum eo susceptis, inverecunde adeo debacchati sunt in eum mendaciis, ut digni sint qui uno hoc crimine condemnentur".

(52). - Flávio Josefo - Vita, 3: "|...l, veniebam in amicitiam Alituri, (erat autem hic mimorum actor in magna apud Neronem gratia, genere, Iudaeus, perque eum ubi Poppeae uxoris Caesaris innotuit, id quam ocissime ago ut mels apud ipsam precibus solventur sacerdotes. Quumque praeter hoc beneficium magnis muneribus cohonestatus essem a Poppea in patriam revertebar".

(53) . - Flávio Josefo - Antiq. Iud:, XIV, 10, 6 et seq.; Bellum Iudaicum, VI, 2; Filon - Legatio ad Caium, 23.
} 
que não exclui que houvesse outras (54) além das atestadas. Cada sinagoga possuia ainda a própria casa de oração, chamada especificadamente proseuché (= oratório; "sinagoga" na acepção moderna) (55). Cada proseuché era regida por um govêrno constituido de dignidades próprias, fato hoje certificado pelas inscrições epigráficas até agora descobertas (56), e por onde se deduz o vigor e o florescimento imperturbado das instituições sócio-religiosas da diáspora hebraica em Roma .

Como índice da ambientação social do elemento hebreu em Roma é importante relevar que das quinhentas e poucas inscrições hebraicas vindas à luz até o momento, setenta e cinco por cento são redigidas em grego; vinte e três por cento em latim; uma dúzia apenas trazem o refrão augural shalom al Yisrael; uma única é esculpida bilngüe, levando um metade da inscrição em grego e a outra em aramaico; e só uma redigida exclusivamente em aramaico (57). Isso vem a comprovar que o emprêgo da língua "sagrada" de Israel, pelo menos nas inscrições, tinha pràticamente desaparecido em favor da grega que se tornara a forma lingüística na tradução da Bíblia chamada comumente Septuaginta.

E' sabido que a Bíblia fôra traduzida para o grego em face das exigências religiosas dos judeus de Alexandria e do Egito, entre os quais o conhecimento do hebraico parece ter sido escasso desde o início, e exceção singularíssima na época páleo-cristã; tanto isso é verdade, que o próprio Fílon, expoente típico do judaismo alexandrino, demonstra não conhecer o hebraico (58).

O helenismo no meio do qual os judeus da diáspora viviam, colocou-os diante da alternativa, ou renunciar ao próprio culto, inconcebível sem as Escrituras Sagradas, ou de "helenizar" estas .

Os judeus do Egito escolheram - coisa de todo natural - a segunda alternativa, traduzindo assim para o grego as Escrituras, que, uma vez traduzidas, foram empregadas quer particularmente quer nas assembléias sinagogais (59) .

$\mathrm{O}$ grego era também a língua dos comerciantes de Alexandria e de certo também do judeu que exercia, plebeio sermone, o seu comércio vendendo fósforos em troca de cacos de vidro (60) e da andrajosa judia que por poucos óbolos interpretava os sonhos (61); e a mesma

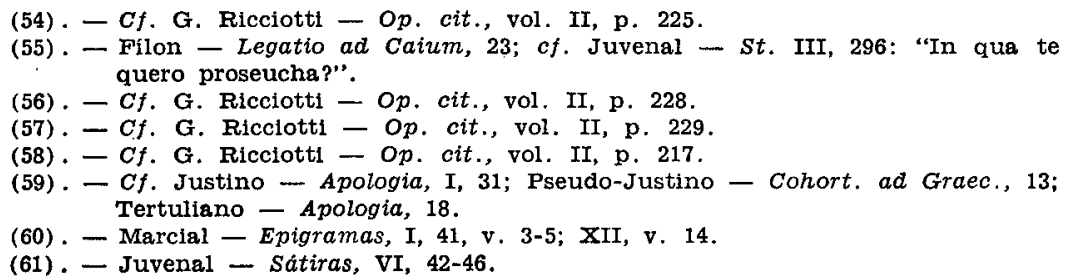


língua se empregava provàvelmente no culto sinagogal a exemplo de Alexandria, exceção feita talvez para a synagoga hebraeorum, que se compunha, com tôda verossemelhança, de elementos que falavam ùnicamente o hebraico (aramaico), porque chegados há pouco da Judéia a Roma (62).

De resto, quanto ao grego, acontecia o mesmo na liturgia cristã da época, pois ficou por dois séculos como língua oficial da igreja romana, contingência esta advinda da existência do elemento oriental "helenizado", predominante na incipiente comunidade "evangélica" de Roma (63).

(Continua).

(62). - Agostino Amore - "Vittorer I" em Enciclopedia Cattolica, Citta del Vaticano, vol. XII, col. 1542.

(63). - Cf. G. Ricciotti - Op. cit., vol. II, p. 230 e 225. 